\title{
EFFECTS OF HIGH-ENERGY IONIZING RADIATION ON ORGAN SYSTEMS IN HUMAN MEDICINE
}

\author{
Visnovcova $\mathrm{N}^{1}$, Simera $\mathbf{M}^{1}$, Visnovcova $\mathbf{N} \mathrm{Jr}^{2}$, Jakusova $\mathrm{V}^{3}$, Jakus $\mathrm{J}^{1}$.
}

\begin{abstract}
${ }^{1}$ Department of Medical Biophysics, Jessenius Faculty of Medicine in Martin, Comenius University, ${ }^{2}$ Clinic of Pediatric Surgery, Jessenius Faculty of Medicine in Martin, Comenius University and University Hospital Martin,

${ }^{3}$ Institute of Public Health, Jessenius Faculty of Medicine in Martin, Comenius University, Slovak Republic
\end{abstract}

\section{A b s t r a c t}

The aim of our study was to investigate acute post-radiation changes after therapy with ionizing radiation manifested by erythema or dry, squamous and scurfy skin on a breast. We observed 100 female patients suffering from an early stage of breast carcinoma. The entering criteria were: age below 70 years, $100 \%$ of the Karnofsky s Score, no tumor bilaterality, tumor in the stage of T1 or T2. The female patients had finished nonradical surgery consisting from quadrantectomy and deviation of the axilla. Our results showed relationships between the localization and the level of breast skin change as well as between adjuvant chemotherapy and the level of breast skin change and, finally, between the size of the average dose of high energy radiation and the level of breast skin change.

Key words: radiotherapy, breast skin change, skin erythema, total dose of radiation

\section{INTRODUCTION}

Radiotherapy is, after surgery, the second oldest way of treatment of breast cancer. Historically, radiation therapy (doses and fields) were selected empirically based mainly on experience of empiric guidelines neglecting the underlying anatomy, physiology and dosimetry (1). Over $90 \%$ of female patients treated with radiotherapy have suffered in different extent from development of skin reactions, mostly during or shortly after the treatment with ionizing radiation (2). In literature there is not enough information about undesirable effects of ionizing radiation on tissues and organs since they are described more frequently as a part of a treatment schedule (3).

Since there are different responses to ionizing radiation between healthy and malignant tissues the oncologists have endeavoured to classify and explain the core of the pathophysiological mechanism of undesirable post-radiation changes. The work of Stone (1948) was the first to clasify late undesirable side effects on tissues following radiation by fast neutrons. Also Lawrence (1970) decribed scoring criteria for late undesirable side effects caused by fast neutrons. Investigators from the European Organization for Research and Treatment of Cancer (EORTC), headed by William Duncam from Western General Hospital of Edinburgh, created common criteria in anticipation of joint studies. Radiation Therapy Oncology Group (RTOG) protocols were introduced in 1980. Although the RTOG began to use these criteria in reporting toxicity in patients enrolled in all studies from 1981 (beginning with RTOG Protocol 8115), the criteria became a published part of the protocols only in 1983 (4). These criteria were launched into practice in 1995 and are used nowadays for acute and chronic toxic undesirable side effects for all organ systems.

Address for correspondence:

Nadežda Višňovcová, Department of Medical Biophysics, Jessenius Faculty of Medicine, Comenius University, Mala Hora Str. N. 4, 03601 Martin, Slovakia

e-mail: nvisnovcova@jfmed.uniba.sk 


\section{MATERIAL AND METHODS}

We observed 100 female patients suffering from an early stage of mammary gland carcinoma. The entering criteria were: age below 70 years, 100\% of the Karnofsky s Score, no tumor bilaterality, tumor in the stage of T1 or T2. The female patients had finished nonradical surgery consisting from quadrantectomy and deviation (excentration) of the axilla (at $1^{\text {st. }}$ and $2^{\text {nd }}$ level). In the patients of our experimental group adjuvant chemotherapy and then curative radiotherapy were applied. In the patients there were three phototypes of skin (Tab.No3) which were classified and consulted with the dermatologist. Median of observation of the patients was 5 weeks.

Radiotherapy was applied to all patients by means of high-energy linear accelerator (CONCOR f. Siemens ), the high-energy of X-rays was $6 \mathrm{MeV}$ and $18 \mathrm{MeV}$ in an average total dose (TD) of $43.44 \pm 1,07 \mathrm{~Gy}$. High-energy electrons were accelerated to 6 and $9 \mathrm{MeV}$. TD of 11.6 \pm 0.33 Gy was applied as "boots". The patients were irradiated by 2 tangential technic fields on the breast area. In our group the patients underwent radiotherapy along with conventional fractionation schedule: 2.0 Gy daily, 5 times in week, 25 fractions within 33 days. The "boots" was applied in all patients (Fig. 1).

Chemotherapeutic treatment started after the surgery and fluorouracil/doxorubicin/ cyclofosfamide (FAC) and fluorouracil/epirubicin/cyclofosfamide (FEC) chemotherapeutic schedule was used within the length of $2-4$ cycles.

Statistical evaluation: Pearson Chi-kvadrat test

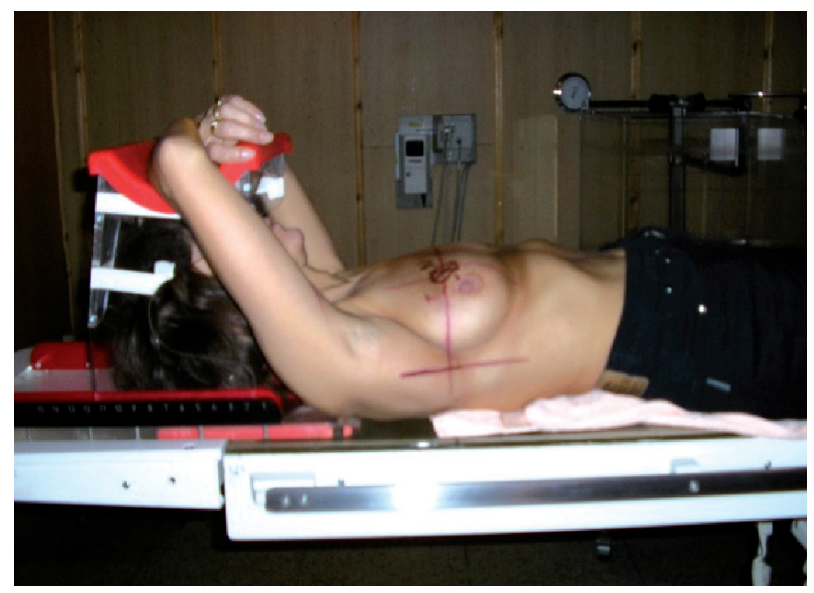

Fig. 1 Position of patient during radiotherapy

(Oncologic Centre, University Hospital in Martin, published with patient's permission)

\section{RESULTS}

During and after adjuvant curative radiotherapy we observed local acute toxic reactions on patient s skin. Toxicity was evaluated in accordance with RTOG/EORTC for clasification of acute toxicity. Toxicity was estimated clinically in cooperation with a dermathologist. We assessed acute toxic reaction on the skin both within and out of irradiated fields. We aimed to determine the following parameters: an average dose of high energy radiation and the level of breast skin change, the relationship between localization and the level of breast skin change, as well as the relationship between skin phototype and the level of breast skin change and the relationship between adjuvant chemotherapy treatment and the level of breast change. 
The $1^{\text {st }}$ parameter we observed an average dose of high energy radiation and the level of breast skin change (No. 1 and 2). The change was observed using a light microscope in accordance with RTOG/EORTC. Level 1 of breast skin change appeared at an average dose of 37 Gy and level 2 of breast skin change was visible at an average dose of 44 Gy ( Fig.2).

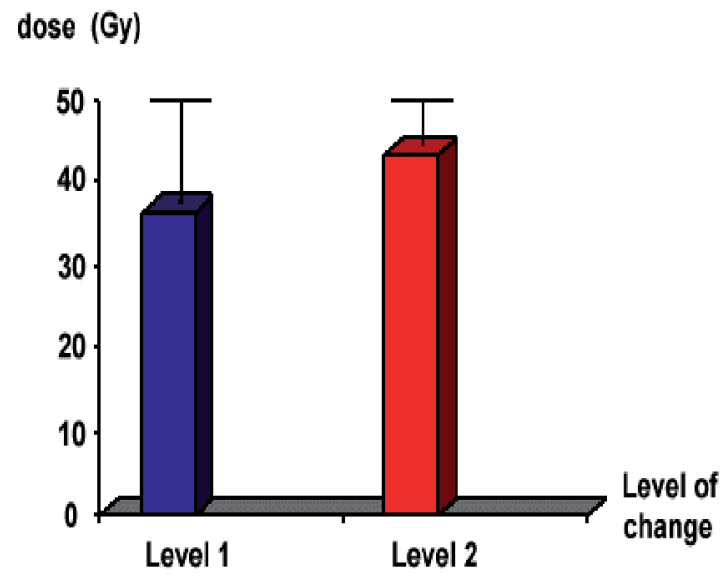

Fig.2 An average dose of high energy radiation and the level of breast skin change (No. 1 and 2), with median 37 Gy for 1 level and 44 Gy for 2 level.

The $2^{\text {nd }}$ parameter was dependence of skin phototype and an average dose on a level of change on the breast skin. In our experimental group we had patients with 3 skin phototypes (No.1 light or ginger hair, blue eyes, light skin , No.2 flaxen or light brown hair, green or gray eyes, light skin, No.3 brown or black hair, brown or black eyes, brown or black eyes, dark skin).

There was a tendency to prove a significant relationships in phototype No.1 for the level of change 1 and 2. It corresponds with clinical experience that in patients with light /blond hair and blue eyes there is a higher possibility to suffer from postradiation changes on the skin and, in addition, they have the worst progress of sickness in comparison with patients with dark hair and dark eyes. There was no significant dependence between phototypes No. 2 and No. 3 and the levels of skin breast change No. 1 and No. 2. (Tab.1)

Table 1 Dependence of phototype and average dose and a level fo change on the breast skin. Tendency for first phototype to change of level 1 and 2.

\begin{tabular}{|l|l|l|l|}
\hline $\begin{array}{l}\text { Phototype } \\
\text { Level of change 1 } \\
\text { Level of change 2 }\end{array}$ & $\begin{array}{l}\text { No.1 } \\
\text { ns (p 0.127) } \\
\text { ns (p 0.1) }\end{array}$ & $\begin{array}{l}\text { No.2 } \\
\text { ns (p 0.259) } \\
\text { ns (p 0.610) }\end{array}$ & $\begin{array}{l}\text { No.3 } \\
\text { ns (p 0.605) } \\
\text { ns (p 0.163) }\end{array}$ \\
\hline
\end{tabular}

The $3^{\text {rd }}$ observed parameter was the relationship between localization and the level of breast skin change (Table 2). We had predicted that the area of intermammar linea and papilla will be the most frequent acute area of postradiation breast skin change.

Our results showed that the areas of intermammar linea are significantly affected by level change No.1, No.2 and areas of papila are significantly affected by level change No. 1. 
Table 2 Relationship between localization and the level of a breast skin change

\begin{tabular}{|l|l|l|c|c|}
\hline Level of change & Intermamar linea & Papilla & Area of all breasts & Axilla \\
No.1 & p 0.001 & p 0.003 & ns & ns \\
No.2 & p 0.003 & ns & ns & ns \\
\hline
\end{tabular}

The $4^{\text {th }}$ observed parameter was the relationship between adjuvant chemotherapy treatment (Table 3) and the level of breast skin change. Our results showed that presence of applicated adjuvant chemotherapy significantly affected presence of level change 1.

Table 3 Relationship between adjuvant chemotherapy treatment and the level of breast skin change. Type of chemotherapy: FAC (fluorouracil/doxorubicin/cyclofosfamide) FEC(fluorouracil/epirubicin/cyclofosfamide). Statistic by Kruskal - Wallis test

\begin{tabular}{|l|l|l|} 
Level & Chemotherapy schedule & Relationship \\
No.1 & FAC, FEC & p 0.033 \\
No. 2 & FAC, FEC & ns \\
\hline
\end{tabular}

\section{DISCUSSION}

Our aim was a clinical study focusing on treatment by means of high energy ionizing (photons and electrons) radiations. First level of skin change appeared with an average dose of 37 Gy and the second level at an average dose of 44 Gy (Fig.2). The occurrence of acute postradiation skin changes on breast are similar but delyed with high-energy X-rays photons and electrons in comparison with high-energy megavolt Cobalt ${ }^{60}$ radiation, where a time of skin change is faster (5). There is a reason to use continual radiotherapy without interruption to prevent postradiation skin changes. Interruption of radiotherapy is not supported by radiobiology findings because it supports growth of tumor cells and may shorten lives of oncology patients (6). Although clinical experience (7) have shown a higher predisposition for skin changes in women with blue eyes and blond hair (Tab.1), the skin phototype has no time influence on an occurrence of acute postradiation skin changes .

We proved that local skin breast changes in the area of intermammar linea and papila were affected in a highly significant manner. Presence of level change No.1, No.2 was affected significantly in evaluation of local skin breast changes in intermammar linea and level change No.1 of papila vs the whole breast area (Tab. 2).

It is important to make prevention and care for breast skin during and after radiotherapy (8). The relationship of adjuvant chemotherapy and subsequent curative radioterapy showed that adjuvant chemotherapy significantly affected the presence of level change No.1 visible on the breast skin (Tab.3). It means that in women who were treated with adjuvant chemotherapy prior to the high-energy radiation treatment there was a higher risk of occurrence of undesirable skin effects (9).

\section{CONCLUSION}

On the basis of our results, we proposed standards for skin care during and after radiotherapy. However, there is still no appropriate skin care standard in clinical practice. We hope that our results will help to make a progress in skin care before, during and after radiotherapy in clinical practice. 


\section{REFERENCES}

1. Lawrence, B., Marks, MD., Ellen, D., Jackons, A.: Use normal tissue complication probability modles in clinic. In: Radiation Oncology Biology Physic, 2010, 76, (3) 10-19.

2. D'haese $\mathrm{S}$ et al.: Management of skin reactions during radiotherapy in Flanders (Belgium): A study of nursing practice before and after the introduction of a skin care protocol. Eur $J$ Oncol Nurs, 2009. doi: 10.1016/j.ejon.2009.10.006

3. Hopewell JW.: The skin, its structure and response to ionizing radiation. In: Radiation Oncology Biology, Physic 1990 Apr, 57(4), 751-73.

4. Hoeller U, Tribius S, Kuhlmey A, Grader K, Fehlauer F, Alberti W.: Increasing the rate of late toxicity by changing the score ? A comparison of RTOG/EORTC toxicity by changing the score? A comparison of RTOG/EORTC and LENT/SOMA scores. In: Radiation Oncology Biology Physic, 2003, 55, 1013-8.

5. Steel G.: Basic clinical radiobiology, 3rd edition. Arnold, London 2002, 192-204.

6. Back, M., Guerrieri, M., et al.: Impact of Radiation Therapy on Acute Toxicity in Breast Conservation Therapy for early Breast cancer. In: Clinic Oncology, 2004, 16, 12-6.

7. Emami, B., Lyman, J., Brown, A., et al.: Tolerance of normal tissue to therapeutic irradiation. In: Radiation Oncology Biology Physic, 1991, (21), 109-122.

8. Malkinson, FD., Keane, JT.: Radiobiology of the skin: review of some effects on epidermis and hair. In: Invest Dermatology, 2001, 77(1), 133-8.

9. Weissberg, MT., Dahmke, L., Schem, C., et al.: In vitro effects of imatinib mesylate on radiosenzitivity and chemosenzitivity of breast cancer cells. In: BMC Cancer, 2010, 9(10), 412-14.

\section{Acknowledgement}

This work was supported by the Slovak Research and Development Agency under the contract No. APVV-0189-11 (prof. Jakus)

Received: August, 26, 2013

Accepted: December, 18, 2013 